\title{
Protein arginine methyltransferase 5 is associated with malignant phenotype and peritoneal metastasis in gastric cancer
}

\author{
MITSURO KANDA, DAI SHIMIZU, TSUTOMU FUJII, HARUYOSHI TANAKA, \\ MASAHIRO SHIBATA, NAOKI IWATA, MASAMICHI HAYASHI, DAISUKE KOBAYASHI, \\ CHIE TANAKA, SUGURU YAMADA, GORO NAKAYAMA, HIROYUKI SUGIMOTO, \\ MASAHIKO KOIKE, MICHITAKA FUJIWARA and YASUHIRO KODERA \\ Department of Gastroenterological Surgery (Surgery II), Nagoya University \\ Graduate School of Medicine, Nagoya 466-8550, Japan \\ Received April 16, 2016; Accepted May 31, 2016
}

DOI: $10.3892 /$ ijo.2016.3584

\begin{abstract}
Identification of novel gastric cancer (GC)-related molecules is necessary to improve management of patients with GC in both diagnostic and therapeutic aspects. The aim of the present study was to determine whether protein arginine methyltransferase 5 (PRMT5) acts as an oncogene in the progression of GC and whether it serves as a novel diagnostic marker and therapeutic target. We conducted global expression profiling of GC cell lines and RNA interference experiments to evaluate the effect of PRMT5 expression on the phenotype of GC cells. We analysed tissues of 179 patients with GC to assess the association of PRMT5 mRNA levels with clinicopathological factors. Differential expression of PRMT5 mRNA by GC cell lines correlated positively with the levels of GEMIN2, STAT3 and TGFB3. PRMT5 knockdown reduced the proliferation, invasion and migration of a GC cell line. PRMT5 mRNA levels were significantly higher in GC tissues than the corresponding adjacent normal tissues and were independent of tumour depth, differentiation and lymph node metastasis. High PRMT5 expression was an independent risk factor of positive peritoneal lavage cytology (odds ratio 3.90, $\mathrm{P}=0.003$ ) and decreased survival. PRMT5 enhances the malignant phenotype of GC cell lines and its expression in gastric tissues may serve as a biomarker for patient stratification and a potential target of therapy.
\end{abstract}

\section{Introduction}

Although the incidence of gastric cancer (GC) is declining, it is the fifth most common cancer after cancers of the lung, breast,

Correspondence to: Dr Mitsuro Kanda, Department of Gastroenterological Surgery (Surgery II), Nagoya University Graduate School of Medicine, 65 Tsurumai-cho, Showa-ku, Nagoya 466-8550, Japan

E-mail:m-kanda@med.nagoya-u.ac.jp

Key words: gastric cancer, protein arginine methyltransferase 5, peritoneal metastasis, biomarker colon and prostate, and GC is the third leading cause of cancer deaths (1-3). Although palliative chemotherapy and surgery are beneficial, the outcome of GC remains dismal (4-6). The high mortality of GC is explained by our poor understanding of its mechanism of progression and the lack of suitable diagnostic markers that hinder diagnosis before the disease reaches an advanced stage $(7,8)$. GC represents a biologically and genetically heterogeneous group of tumours that are induced by multiple factors that deregulate cell signalling pathways, which leads to the acquisition of malignant phenotypes such as increased cell proliferation, inhibition of apoptosis and enhanced invasiveness (9-11). Identification of novel molecules is therefore required to improve diagnosis and therapy.

Protein arginine methyltransferase 5 (PRMT5) catalyses the symmetrical dimethylation of arginine residues of histone and non-histone substrates (12-14). Because PRMT5 is implicated in diverse cellular and biological processes such as transcriptional regulation, RNA metabolism, ribosome biogenesis, Golgi apparatus homeostasis and cell cycle regulation, PRMT5 is generating increased interest in the field of cancer research $(12,15,16)$. For example, PRMT5 is expressed at higher levels compared with normal tissues in leukemias, lymphomas and gliomas as well as in ovarian, breast, prostate and lung cancers $(13,14,17-20)$. In contrast, the expression levels of PRMT5 in gastroenterological malignancies and the biological function of PRMT5 remain to be determined.

To address these questions, we hypothesized that PRMT5 is linked to the malignant phenotype of GC. The aim of the present study was to determine whether PRMT5 acts as an oncogene in GC. This study provides insight into the contribution of PRMT5 to the malignant behavior of GC, and provides a rationale for targeting this enzyme in GC.

\section{Materials and methods}

Sample collection. Ten GC cell lines (AGS, KATOIII, MKN1, MKN45, MKN74, N87, NUGC2, NUGC3, NUGC4 and SC-6-JCK) and the non-tumourigenic epithelial cell line (FHs74) were obtained from the American Type Culture Collection (ATCC; Manassas, VA, USA), Tohoku University, Japan, or were established at our institute. Cell lines were 
cultured at $37^{\circ} \mathrm{C}$ in Dulbecco's modified Eagle's medium (DMEM; Sigma-Aldrich, St. Louis, MO, USA) supplemented with $10 \%$ fetal bovine serum (FBS) in an atmosphere containing $5 \% \mathrm{CO}_{2}$ (21). Primary GC tissues and the corresponding non-cancerous adjacent tissues were collected from 179 patients who underwent gastric resection for GC without neoadjuvant therapy at Nagoya University Hospital between 2001 and 2010. The tissue samples were immediately frozen in liquid nitrogen and stored at $-80^{\circ} \mathrm{C}$. The specimens were classified histologically according to the 7th edition of the Union for International Cancer Control (UICC) classification system. Since 2006, adjuvant chemotherapy using S-1 (an oral fluorinated pyrimidine) is used to treat all patients with UICC stage II/III GC unless contraindicated by the patient's condition (22-24). This study conformed to the ethical guidelines of the World Medical Association Declaration of Helsinki, Ethical Principles for Medical Research Involving Human Subjects. Written informed consent for the use of clinical samples and data, as required by the institutional review board at Nagoya University, Japan, was obtained from all patients.

Analysis of PRMT5 mRNA expression. PRMT5 mRNA levels were determined using a quantitative real-time reverse-transcription polymerase chain reaction (qRT-PCR) assay. Total RNAs (10 $\mu \mathrm{g}$ per sample), which were isolated from 12 cell lines and 179 primary GC tissues as well as the corresponding non-cancerous adjacent tissues, were used to generate cDNAs. The cDNAs were amplified using PCR primers specific for PRMT5 as follows: sense 5'-TCTCATGGTTTCCCATCC TC-3' in exon 16 and antisense 5'-CCTTCTTGGAATTGCT GCAT-3' in exon 17 , which amplify a 102-bp product. The RT-PCR amplification reaction was performed as follows: initial denaturation at $95^{\circ} \mathrm{C}$ for $10 \mathrm{~min}, 40$ cycles at $95^{\circ} \mathrm{C}$ for $10 \mathrm{sec}$ and at $60^{\circ} \mathrm{C}$ for $30 \mathrm{sec}$. All samples were tested in triplicate, and samples without template were included in each PCR plate as negative controls. A SYBR-Green PCR Core reagents kit (Applied Biosystems, Foster City, CA, USA) was used to perform qRT-PCR, and real-time detection of the SYBR-Green fluorescence emission intensity was conducted using an ABI StepOnePlus Real-Time PCR system (Applied Biosystems). The levels of glyceraldehyde-3-phosphate dehydrogenase $(G A P D H)$ mRNA were quantified in each sample for standardization. The expression level of each sample was calculated as the value of PRMT5 mRNA divided by that of GAPDH mRNA (25).

PCR array analysis of differential gene expression. To analyse gene expression by $10 \mathrm{GC}$ cell lines and the FHs74 cell line, we used the Human Epithelial to Mesenchymal Transition (EMT) $\mathrm{RT}^{2}$ Profiler PCR Array (Qiagen, Hilden, Germany) of 84 key genes, including those that encode the proteins as follows: transcription factors, extracellular matrix proteins as well as proteins involved in the EMT, cell differentiation, morphogenesis, growth, proliferation, migration, cytoskeleton and major signalling pathways (26).

Knockdown of PRMT5 expression using a small interfering RNA (siRNA). NUGC3 and AGS cells were cultured in a 24 -well plate $\left(5 \times 10^{4}\right.$ cells $\left.\mathrm{ml}^{-1}\right)$. Cells were transiently transfected the next day with either $30 \mathrm{nM}$ of an siRNA specific for
PRMT5 (siPRMT5; 5'-CAGCCACUGAUGGACAAUCUGG AAU-3' and 5'-CCGGCUACUUUGAGACUGUGCUUUA-3') or a control siRNA (siControl) using LipoTrust EX Oligo (Hokkaido System Science, Sapporo, Japan). After transfection, cells were cultured in serum-free DMEM for $72 \mathrm{~h}$ and used in the western blot and functional analyses. Western blot analysis using a rabbit anti-PRMT5 polyclonal antibody (Cell Signaling Technology, Beverly, MA, USA) diluted 1:1,000 was performed as previously described (27).

Cell proliferation assay. Cell proliferation was evaluated using the Premix WST-1 Cell Proliferation assay system (Takara Bio Inc., Shiga, Japan). NUGC 3 and AGS cells $\left(5 \times 10^{3}\right.$ cells/well) were seeded into 96-well plates in DMEM supplemented with $2 \%$ FBS for 7 days. The optical density of the solution in each well was measured on days 1,3 and 5 for NUGC 3 cell, and 1, 3, 5 and 7 for AGS cell following addition of $10 \mu \mathrm{l}$ of WST-1. In addition, the $\%$ decrease by siPRMT5 in proliferation was calculated as [1 - (fold change of siPRMT5/fold change of untransfected)] x 100 on every measurement day.

Cell invasion assay. The ability of GC cells to invade Matrigel was determined using BioCoat Matrigel invasion chambers (BD Biosciences, Bedford, MA, USA) according to the manufacturer's protocol. NUGC 3 and AGS cells $\left(2.5 \times 10^{4}\right.$ cells/well $)$ were seeded into the upper well of the chamber in serum-free DMEM. After $48 \mathrm{~h}$, cells on the lower surface of the membrane were fixed, stained and counted using a microscope (x200 magnification, five randomly selected fields).

Wound-healing assay. The migration of GC cells was evaluated using wound-healing assays. NUGC 3 and AGS cells $\left(2 \times 10^{4}\right.$ cells/well) were seeded into 12 -well plates in serum-free DMEM using the ibidi Culture insert method (ibidi GmbH, Martinsried, Germany) to establish wound gaps of a defined width. After $24 \mathrm{~h}$, the insert was removed, and the width of the wound was measured at $200-\mu \mathrm{m}$ intervals (10 per well, $\mathrm{x} 40$ magnification) according to cell-dependent time intervals.

Statistical analysis. The Chi-square and Mann-Whitney tests were used to compare the differences between the two groups. The significance of a correlation between two variables was assessed using Spearman's rank correlation coefficient. Risk factors for positive peritoneal lavage cytology were evaluated using binomial logistic analysis. Overall survival rates were calculated using the Kaplan-Meier method, and the difference in survival curves was analysed using the log-rank test. We performed multivariable regression analysis to detect prognostic factors using the Cox proportional hazards model, and variables with a $\mathrm{P}$-value of $<0.05$ were entered into the final model. All statistical analyses were performed using JMP v.10 software (SAS Institute, Inc., Cary, NC, USA). A P-value of $<0.05$ was considered statistically significant.

\section{Results}

Differential gene expression by GC cell lines. Expression levels of PRMT5 mRNA were heterogeneous among GC cell lines. The levels of PRMT5 mRNA were $>2$-fold higher in AGS, KATOIII, MKN1, MKN45 and NUGC3 cells compared 
A
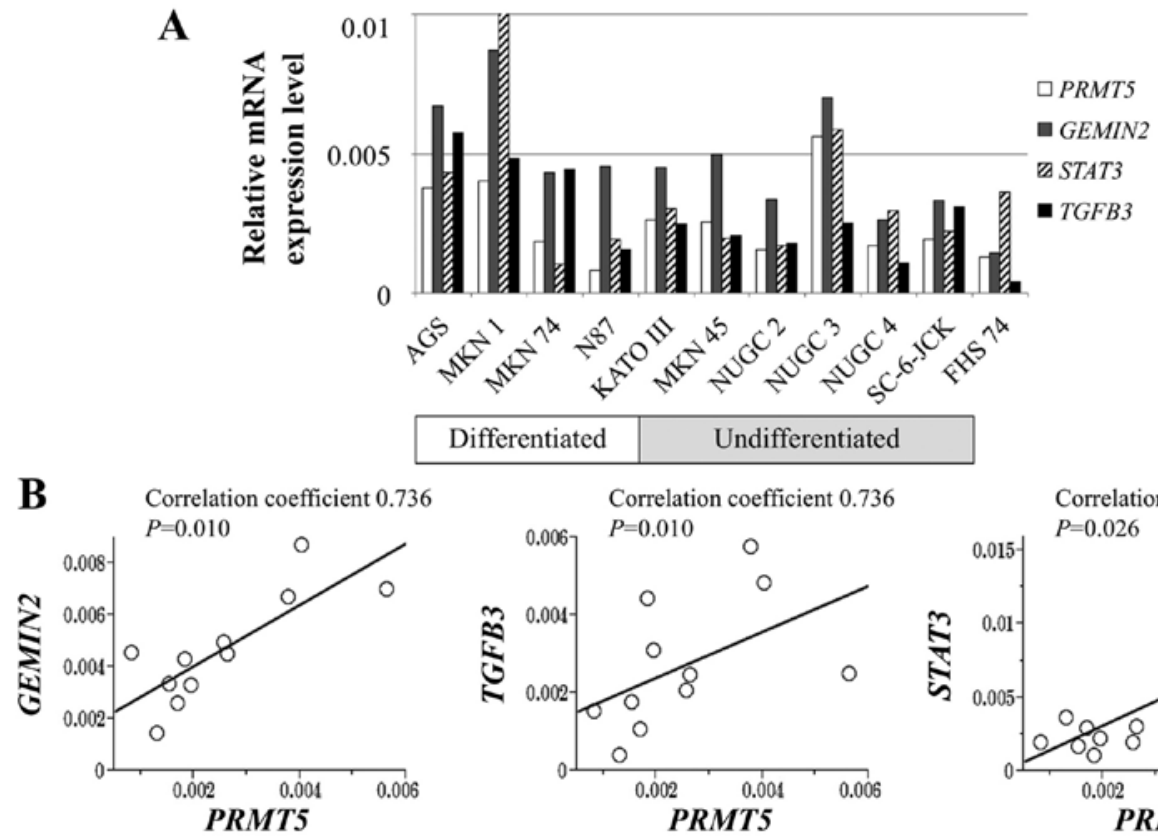

$$
\begin{array}{|l|l|l|l|l}
\text { Differentiated } & \text { Undifferentiated } \\
\hline
\end{array}
$$
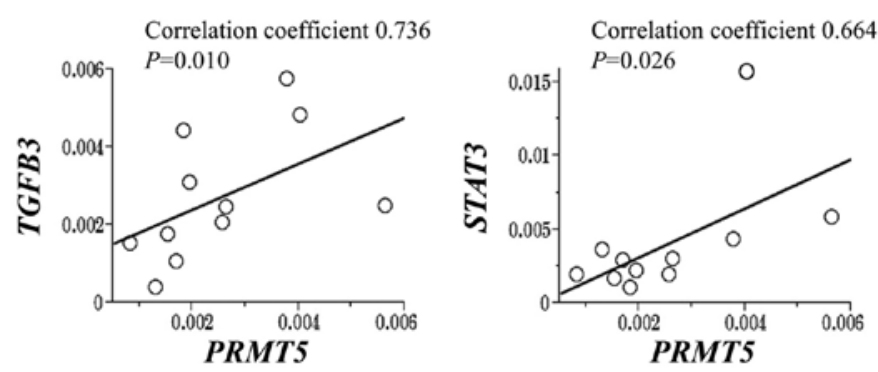

Figure 1. Expression analysis of cell lines. (A) Expression of PRMT5 and genes expressed at similar differential levels were identified using PCR array analysis. (B) Analysis of the correlation between the mRNA expression levels of PRMT5 and those of GEMNIN2, TGFB3 and STAT3.

A

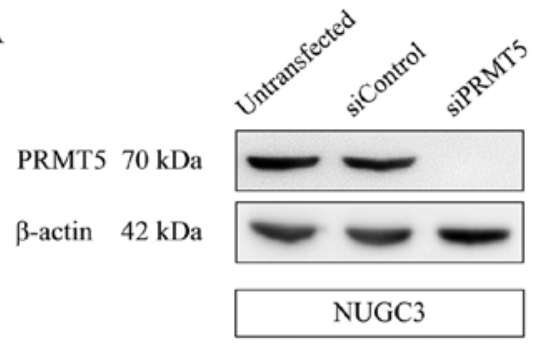

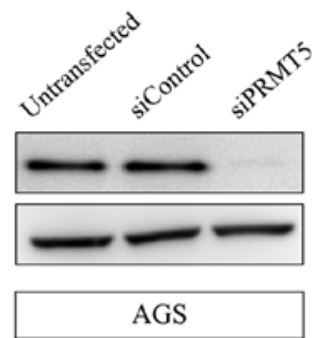

B

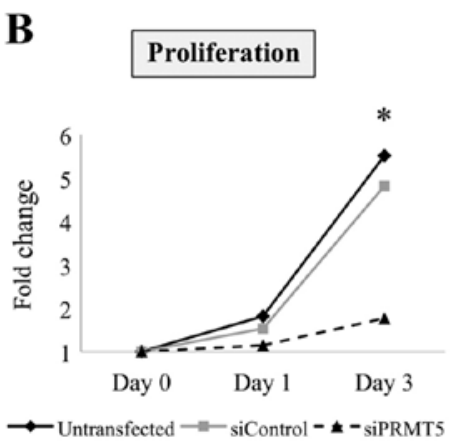

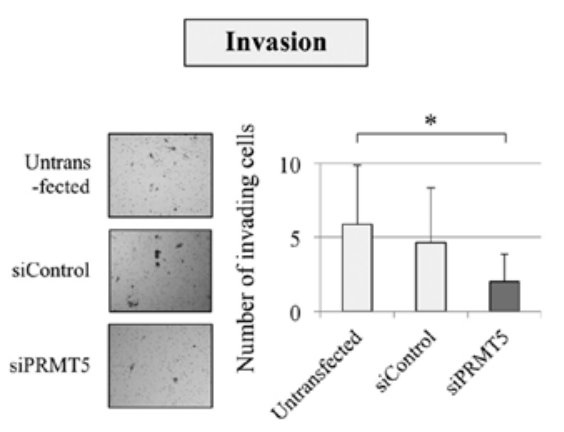

Figure 2. Effects of siRNA-mediated knockdown of PRMT5 expression. (A) Confirmation of siRNA-mediated PRMT5 knockdown was determined using western blot analysis. (B) Cell proliferation, invasion and wound healing assays for the NUGC3 cell. PRMT5 siRNA inhibited significantly the proliferation, invasion and migration of NUGC 3 cells. ${ }^{*} \mathrm{P}<0.05$.

with the control FHs74 cells, whereas N87 cells showed lower PRMT5 expression level than FHs74 cells (Fig. 1A). PRMT5 mRNA levels did not differ according to the extent of differentiation of the GC cells. PCR array analysis revealed that mRNAs encoding gem (nuclear organelle) associated protein 2 (GEMIN2), signal transducer and activator of transcription 3 (STAT3) and transforming growth factor beta 3 (TGFB3) were expressed at levels that correlated significantly with those of the mRNA encoding PRMT5 (Fig. 1B).
Effect of PRMT5 knockdown on the malignant phenotype of GC cells. Inhibition of PRMT5 expression using a specific siRNA was conducted to evaluate the function of PRMT5 in GC cells. NUGC3 (undifferentiated) and AGS (differentiated) cells were selected as PRMT5-overexpressed cells from the qRT-PCR results. The effect of PRMT5 knockdown was confirmed using western blotting assay (Fig. 2A). We evaluated the proliferation, invasion and migration of NUGC3 and AGS cells. Knockdown of PRMT5 expression significantly 

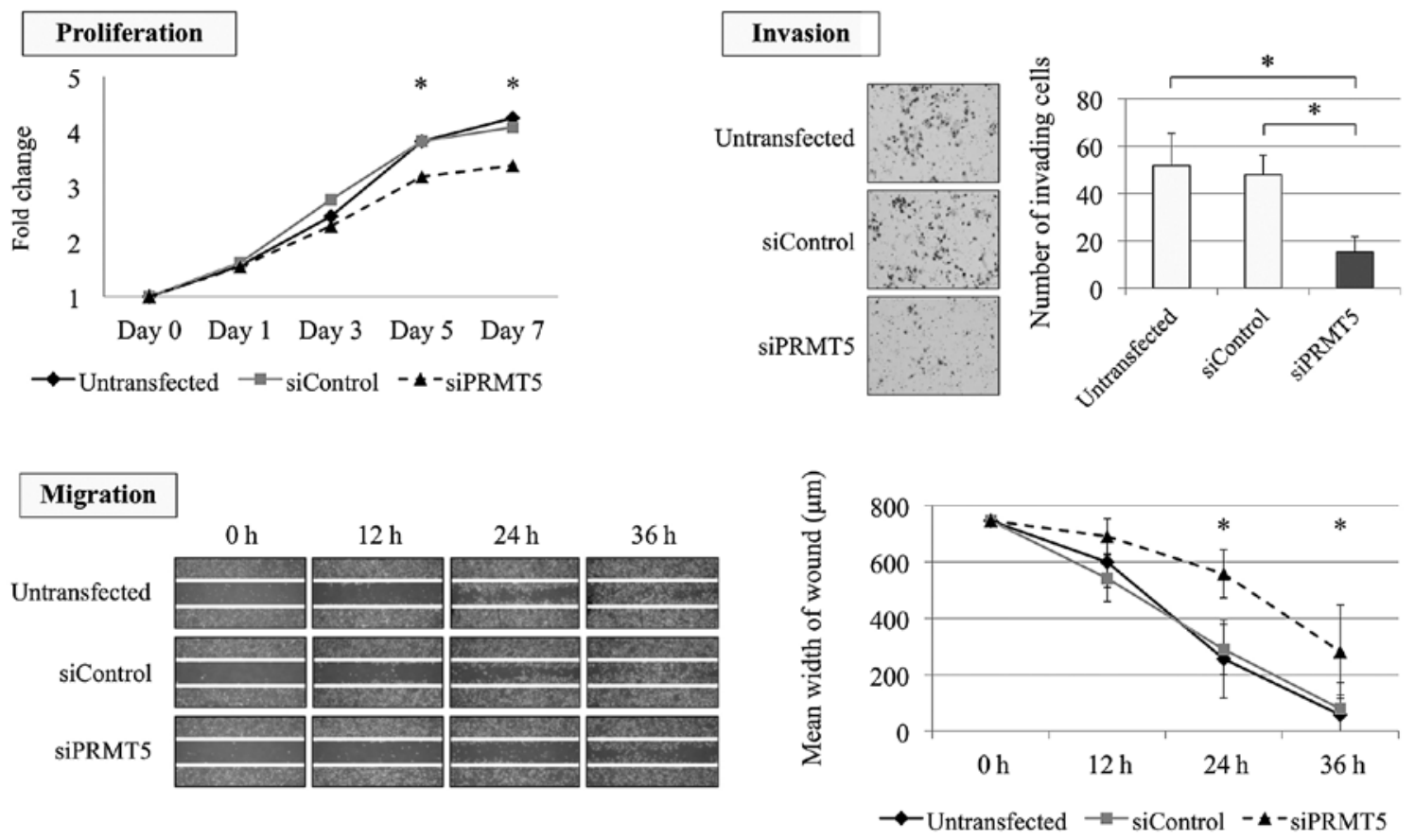

Figure 3. Cell proliferation, invasion and wound healing assays for the AGS cells. Knockdown of PRMT5 significantly reduced the proliferation, invasion and migration abilities of AGS cell. ${ }^{*} \mathrm{P}<0.05$.

A

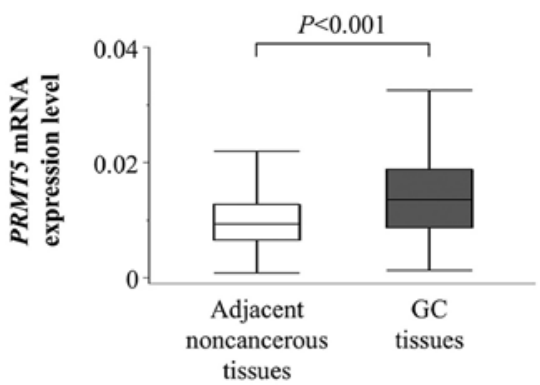

B

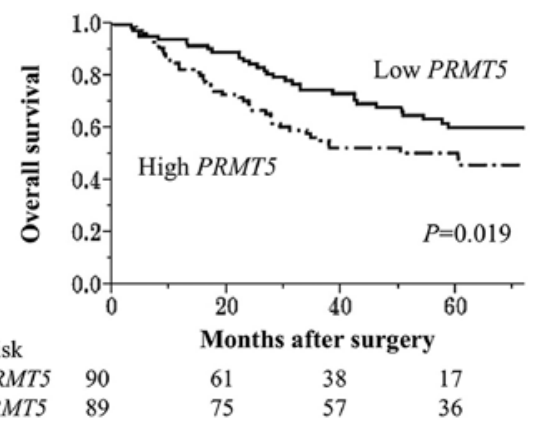

Figure 4. Expression of PRMT5 in clinical samples. (A) The levels of PRMT5 mRNA were elevated in GC tissues compared with the corresponding adjacent non-cancerous tissues. (B) Patients in the high PRMT5 expression group were more likely to have poorer overall survival compared with those in the low PRMT5 expression group. GC, gastric cancer.

decreased the proliferation ability of NUGC3 cell with 82 and $83 \%$ decrease on day 1 and 3, respectively (Fig. 2B). Invasion and migration abilities of NUGC3 cells were also reduced by inhibition of PRMT5 compared with the untransfected and siControl-transfected cells (Fig. 2B). Similarly, the proliferation ability of AGS cells was significantly decreased by PRMT5 knockdown with 23 and $27 \%$ decrease on day 5 and 7 , respectively (Fig. 3). The invasion and migration of AGS cells were also significantly decreased after inhibition of PRMT5 expression (Fig. 3).

Clinical implications of PRMT5 expression in tumour tissues. The mean level of PRMT5 mRNA was significantly higher in 179 GC tissues compared with those of the corresponding adjacent normal tissues (Fig. 4A). Patients were classified into high and low PRMT5 expression groups according to the median value of PRMT5 mRNA levels. PRMT5 mRNA levels were independent of tumour depth, differentiation and lymph node metastasis, whereas they were significantly and specifically associated with peritoneal lavage cytology (Table I). To investigate further the relationship between high PRMT5 mRNA levels in GC tissues and positive peritoneal lavage cytology, multivariate binomial logistic analysis was conducted and revealed that high PRMT5 mRNA levels were significantly associated with positive peritoneal lavage cytology (odds ratio, 3.90, 95\% confidence interval 1.59-10.2, $\mathrm{P}=0.003$; Table II). Patients with high levels of PRMT5 mRNA ( $n=90)$ were more likely to survive for shorter times compared with those with low levels $(\mathrm{n}=89)$, and their 5 -year survival rates were 51 and $60 \%$, respectively $(\mathrm{P}=0.019$; Fig. $4 \mathrm{~B})$. In the multivariate analysis, lymph node metastasis and positive lavage cytology were identified as independent prognostic factors, but PRMT5 expression was not (hazard ratio $1.54,95$, confidence interval $0.94-2.54, \mathrm{P}=0.086)$.

\section{Discussion}

Arginine methylation is an important posttranslational modification of nuclear and cytoplasmic proteins and plays a vital role in cellular function $(14,28)$. The human genome encodes 11 PRMT isoforms that covalently modify arginine 
Table I. Association between PRMT5 mRNA expression level and clinicopathological parameters in 179 patients.

\begin{tabular}{lccc}
\hline & High & Low & \\
PRMT5 & PRMT5 & \\
& mRNA & mRNA & \\
Variables & in GC & in GC & \\
& tissue (n) & tissue (n) & P-value \\
\hline
\end{tabular}

Age (years)
$<65$
$\geq 65$

42

48

Gender

Male

Female

68

22

Carcinoembryonic

antigen $(\mathrm{ng} / \mathrm{ml})$

$$
\begin{aligned}
& \leq 5 \\
& >5
\end{aligned}
$$

18

73

16

Carbohydrate antigen 19-9 (IU/ml)

$$
\leq 37
$$$$
>37
$$

Tumour location

Entire

Upper third

Middle third

Lower third

0.493

$$
0.756
$$

$$
0.730
$$

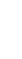

(1)

\subsection{7}

Variables

Table I. Continued.

\begin{tabular}{lccc}
\hline & $\begin{array}{c}\text { High } \\
\text { PRMT5 } \\
\text { mRNA } \\
\text { in GC } \\
\text { tissue (n) }\end{array}$ & $\begin{array}{c}\text { Low } \\
\text { PRMT5 } \\
\text { mRN }\end{array}$ & \\
in GC & \\
tissue (n) & P-value \\
\hline Lymph node metastasis & & & 0.601 \\
Absent & 31 & 34 & \\
Present & 59 & 55 & \\
Peritoneal lavage cytology & & & \\
Negative & 60 & 78 & $<0.001^{\mathrm{a}}$ \\
Positive & 30 & 11 & \\
UICC stage & & & $0.092^{2}$ \\
I & 19 & 20 & \\
II & 14 & 16 & \\
III & 21 & 32 & \\
IV & 36 & 21 & \\
\hline
\end{tabular}

${ }^{a}$ Statistically significant $(\mathrm{P}<0.05)$. GC, gastric cancer; UICC, Union for International Cancer Control.
Tumour size $(\mathrm{mm})$

$<50$

$\geq 50$

Tumour depth (UICC)

$$
\begin{aligned}
& \text { pT1-3 } \\
& \text { pT4 }
\end{aligned}
$$

Histology

Papillary

Well differentiated

Moderately differentiated

Poorly differentiated

Signet ring cell

Mucinous

Differentiation

Differentiated

Undifferentiated

Lymphatic involvement

Absent

Present

0.586

35

54

49

40

0.261

Vessel invasion

Absent

Present

Infiltrative growth type

Invasive growth

Expansive growth residues in histone and nonhistone proteins that contribute to diverse cellular regulatory networks (20). Types I and II PRMTs catalyse monomethylation at the $\omega-\mathrm{NH} 2$ group of arginine; however, they differ in their ability to add the second methyl group, either asymmetrically (type I) or symmetrically (type II) $(13,14,29)$. PRMT5 is a type II PRMT that catalyses the transfer of methyl groups from $\mathrm{S}$-adenosyl methionine to the arginine residues of histones or non-histone proteins and is involved in numerous cellular processes $(19,30)$. Because PRMT5 possesses multiple cellular functions, it is an important determinant of oncological properties of various malignancies $(12-14,17,18)$. In the present study, analyses of the expression levels of PRMT5 and their effects on the phenotypes of GC cell lines, patient characteristics and outcomes were performed to assess the potential of PRMT5 as a novel biomarker and therapeutic target for patients with GC.

Ibrahim et al (18) found that PRMT5 is likely involved in the EMT of lung adenocarcinomas; however, the roles of PRMT5 in the EMT are unknown. In the present study, we conducted PCR array analysis to evaluate the involvement of PRMT5 in the oncological processes, particularly in the EMT that occurs in GC cells. GEMIN2, STAT3 and $T G F B 3$ were identified as genes that were expressed in concert with PRMT5. GEMIN2 (synonym, SIP1) encodes a zinc-finger transcription factor targeting the E2-box on the E-cadherin promoter and acts as a direct transcriptional repressor of E-cadherin $(31,32)$. GEMIN2 acts downstream in EMT-inducing signal transduction pathways activated by growth factors as well as in integrin engagement and hypoxia (33). STAT3 was discovered as a latent transcription factor that is robustly activated by interleukin- 6 and epidermal growth factor $(34,35)$. Numerous studies indicate that STAT3 modulates the expression of important EMT tran- 
Table II. Predictive factors of peritoneal lavage cytology in 179 patients with gastric cancer.

\begin{tabular}{|c|c|c|c|c|c|}
\hline \multirow[b]{2}{*}{ Variables } & \multicolumn{2}{|c|}{ Univariate } & \multicolumn{3}{|c|}{ Multivariate } \\
\hline & OR & P-value & OR & $95 \% \mathrm{CI}$ & P-value \\
\hline \multicolumn{6}{|l|}{ Age (years) } \\
\hline$<65$ & 1.12 & 0.746 & & & \\
\hline \multicolumn{6}{|l|}{ Gender } \\
\hline Female & 1.27 & 0.567 & & & \\
\hline \multicolumn{6}{|l|}{ CEA (ng/ml) } \\
\hline$>5$ & 1.83 & 0.158 & & & \\
\hline \multicolumn{6}{|l|}{ CA19-9 (IU/ml) } \\
\hline$>37$ & 2.59 & 0.024 & 2.17 & $0.76-6.32$ & 0.145 \\
\hline \multicolumn{6}{|l|}{ Tumour location } \\
\hline Lower third & 0.80 & 0.529 & & & \\
\hline \multicolumn{6}{|l|}{ Tumour size (mm) } \\
\hline$\geq 50$ & 3.17 & 0.003 & 1.47 & $0.53-4.17$ & 0.460 \\
\hline \multicolumn{6}{|l|}{ Tumour depth } \\
\hline pT4 & 15.8 & $<0.001$ & 8.51 & $2.66-34.4$ & $<0.001^{\mathrm{a}}$ \\
\hline \multicolumn{6}{|l|}{ Differentiation } \\
\hline Undifferentiated & 2.46 & 0.020 & 1.51 & $0.48-4.88$ & 0.479 \\
\hline \multicolumn{6}{|c|}{ Lymphatic involvement } \\
\hline Present & 9.29 & 0.003 & 1.38 & $0.06-13.7$ & 0.803 \\
\hline \multicolumn{6}{|l|}{ Vessel invasion } \\
\hline Present & 2.28 & 0.025 & 1.45 & $0.55-3.91$ & 0.452 \\
\hline \multicolumn{6}{|l|}{ Infiltrative growth } \\
\hline Invasive & 5.67 & $<0.001$ & 3.43 & $1.26-10.0$ & $0.015^{\mathrm{a}}$ \\
\hline \multicolumn{6}{|c|}{ Lymph node metastasis } \\
\hline Present & 10.3 & $<0.001$ & 3.71 & $0.95-19.8$ & 0.060 \\
\hline \multicolumn{6}{|l|}{ PRMT5 expression } \\
\hline High & 3.55 & $<0.001$ & 3.90 & $1.59-10.2$ & $0.003^{\mathrm{a}}$ \\
\hline
\end{tabular}

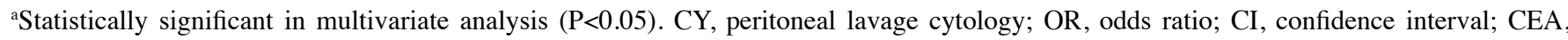
carcinoembryonic antigen; CA19-9, carbohydrate antigen 19-9; UICC, Union for International Cancer Control.

scription factors that integrate signals generated by multiple extracellular stimuli that influence EMT phenotypes (34-36). Mammalian TGF isoforms (TGF- $\beta 1$, TGF- $\beta 2$ and TGF- $\beta 3$ ) share $97 \%$ amino acid sequence identity and signal through activation of TGF- $\beta$ receptors (28). TGF- $\beta$ isoforms play major roles in tumourigenesis mediated by the EMT through regulating cell growth, migration, invasion and metastasis $(28,37,38)$. Although pathway analyses should be mandatory to further identify the involvement PRMT5 in EMT process, our present results might suggest that PRMT5 partially participate in EMT programs through its coordinate expression with other EMT-inducing molecules in GC cells.

There are no reports, to the best of our knowledge, that identify the function of PRMT5 in the malignant phenotypes of GC. We show here that PRMT5 contributed to the cell proliferation in addition to the migration and invasion abilities of GC cell lines. In NUGC3 cells, a significant decrease of proliferation ability by knockdown of siPRMT5 was shown on day 3 , whereas the differences in proliferation ability were exhibited from day 5 in the AGS cells. The possible expla- nations of this time lag were differences in cell-dependent efficacy, quickness and duration of action of siRNA transfection. Although analyses of apoptosis, cell cycle and interaction with the components of intracellular signalling pathways may contribute to understanding the functions of PRMT5 in the malignant phenotypes of GC, our findings support the hypothesis that PRMT5 acts as an oncogene when expressed at high levels and serves as a candidate target for the therapy of GC. To verify our in vitro results, we evaluated the expression of PRMT5 and its clinical implications using surgically resected gastric tissues. PRMT5 was significantly overexpressed in GC tissues compared with the corresponding adjacent normal tissues. Further, patients with high levels of PRMT5 mRNA were more likely to survive for shorter times compared with those without.

We were intrigued by our finding here that PRMT5 expression in patients' GC tissues was strongly associated with positive peritoneal lavage cytology. Peritoneal metastasis is a most frequent and dismal condition in patients with advanced GC and is diagnosed only when macroscopic disseminated 
nodules are found during staging laparoscopy or from findings of positive peritoneal lavage cytology $(6,39)$. Therefore, the availability of specific biomarkers that predict or enable early detection of peritoneal metastasis is anticipated to enhance management of GC. As an important step toward achieving this goal, we show here that the level of PRMT5 mRNA in $\mathrm{GC}$ tissues is an independent risk factor for positive peritoneal lavage cytology. Linitis plastica, serosal invasion (T4) and lymph node metastasis have been reported to be risk factors for peritoneal metastasis of gastric cancer (40-42). In this study, high PRMT5 expression was strongly associated with positive cytology, but independent of these well-known risk factors. This reveals the unique predictive value of PRMT5 for peritoneal metastasis and indicates that GC patients with increased expression of PRMT5 can be categorized into a high-risk group with peritoneal metastasis regardless of tumor types, $\mathrm{T}$ and $\mathrm{N}$ status. The value of PRMT5 expression as a tool to screen for peritoneal metastasis will be enhanced by the development of assays to detect PRMT5 expression in serum and peritoneal fluid.

The present study has certain limitations. First, extensive expression analyses of proteins, particularly ones related to EMT process, that potentially interact with PRMT5 as well as apoptosis assays must be conducted to further understand the biological functions of PRMT5 in GC. Second, this study was limited by the relatively small sample size. To determine the usefulness of PRMT5 expression as a biomarker for GC, analysis of a larger cohort using multiple clinical samples, such as gastric tissues, ascites fluids and serum samples, will be required to deepen our knowledge on clinical significance of PRMT5.

Taken together, our findings indicate that PRMT5 acts as an oncogene in GC by enhancing the malignant phenotype of a cancer cell line. PRMT5 expression in gastric tissues may represent a promising biomarker for identification of patients at high risk, particularly for peritoneal metastasis.

\section{References}

1. Hartgrink HH, Jansen EP, van Grieken NC and van de Velde CJ: Gastric cancer. Lancet 374: 477-490, 2009.

2. Kanda M, Kobayashi D, Tanaka C, Iwata N, Yamada S, Fujii T, Nakayama G, Sugimoto H, Koike M, Nomoto S, et al: Adverse prognostic impact of perioperative allogeneic transfusion on patients with stage II/III gastric cancer. Gastric Cancer 19: 255-263, 2016.

3. Siegel R, Naishadham D and Jemal A: Cancer statistics, 2012. CA Cancer J Clin 62: 10-29, 2012.

4. Leung WK, Wu MS, Kakugawa Y, Kim JJ, Yeoh KG, Goh KL, Wu KC, Wu DC, Sollano J, Kachintorn U, et al; Asia Pacific Working Group on Gastric Cancer: Screening for gastric cancer in Asia: Current evidence and practice. Lancet Oncol 9: 279-287, 2008.

5. Kanda M, Mizuno A, Fujii T, Shimoyama Y, Yamada S, Tanaka C, Kobayashi D, Koike M, Iwata N, Niwa Y, et al: Tumor infiltrative pattern predicts sites of recurrence after curative gastrectomy for stages 2 and 3 gastric cancer. Ann Surg Oncol 23: 1934-1940, 2016.

6. Paoletti X, Oba K, Burzykowski T, Michiels S, Ohashi Y, Pignon JP, Rougier P, Sakamoto J, Sargent D, Sasako M, et al; GASTRIC (Global Advanced/Adjuvant Stomach Tumor Research International Collaboration) Group: Benefit of adjuvant chemotherapy for resectable gastric cancer: A meta-analysis. JAMA 303: 1729-1737, 2010.

7. McLean MH and El-Omar EM: Genetics of gastric cancer. Nat Rev Gastroenterol Hepatol 11: 664-674, 2014.
8. Kanda M, Nomoto S, Oya H, Takami H, Shimizu D, Hibino S, Hashimoto R, Kobayashi D, Tanaka C, Yamada S, et al: The expression of melanoma-associated antigen D2 both in surgically resected and serum samples serves as clinically relevant biomarker of gastric cancer progression. Ann Surg Oncol 23 (Suppl 2): S214-S221, 2016.

9. Jang BG and Kim WH: Molecular pathology of gastric carcinoma. Pathobiology 78: 302-310, 2011.

10. Resende C, Thiel A, Machado JC and Ristimäki A: Gastric cancer: Basic aspects. Helicobacter 16 (Suppl 1): 38-44, 2011

11. Kanda M, Shimizu D, Tanaka H, Shibata M, Iwata N, Hayashi M, Kobayashi D, Tanaka C, Yamada S, Fujii T, et al: Metastatic pathway-specific transcriptome analysis identifies MFSD4 as a putative tumor suppressor and biomarker for hepatic metastasis in patients with gastric cancer. Oncotarget 7: 13667-13679, 2016.

12. Tanaka H, Hoshikawa Y, Oh-hara T, Koike S, Naito M, Noda T, Arai H, Tsuruo T and Fujita N: PRMT5, a novel TRAIL receptorbinding protein, inhibits TRAIL-induced apoptosis via nuclear factor-kappaB activation. Mol Cancer Res 7: 557-569, 2009.

13. Bao X, Zhao S, Liu T, Liu Y, Liu Y and Yang X: Overexpression of PRMT5 promotes tumor cell growth and is associated with poor disease prognosis in epithelial ovarian cancer. J Histochem Cytochem 61: 206-217, 2013.

14. Nicholas C, Yang J, Peters SB, Bill MA, Baiocchi RA, Yan F, Sif S, Tae S, Gaudio E, Wu X, et al: PRMT5 is upregulated in malignant and metastatic melanoma and regulates expression of MITF and $\mathrm{p} 27^{\mathrm{Kip} 1}$. PLoS One 8: e74710, 2013.

15. Aggarwal P, Vaites LP, Kim JK, Mellert H, Gurung B, Nakagawa H, Herlyn M, Hua X, Rustgi AK, McMahon SB, et al: Nuclear cyclin D1/CDK4 kinase regulates CUL4 expression and triggers neoplastic growth via activation of the PRMT5 methyltransferase. Cancer Cell 18: 329-340, 2010.

16. Tee WW, Pardo M, Theunissen TW, Yu L, Choudhary JS, Hajkova P and Surani MA: Prmt5 is essential for early mouse development and acts in the cytoplasm to maintain ES cell pluripotency. Genes Dev 24: 2772-2777, 2010.

17. Han X, Li R, Zhang W, Yang X, Wheeler CG, Friedman GK, Province P, Ding Q, You Z, Fathallah-Shaykh HM, et al: Expression of PRMT5 correlates with malignant grade in gliomas and plays a pivotal role in tumor growth in vitro. $\mathrm{J}$ Neurooncol 118: 61-72, 2014.

18. Ibrahim R, Matsubara D, Osman W, Morikawa T, Goto A, Morita S, Ishikawa S, Aburatani H, Takai D, Nakajima J, et al: Expression of PRMT5 in lung adenocarcinoma and its significance in epithelial-mesenchymal transition. Hum Pathol 45: 1397-1405, 2014

19. Li Y, Chitnis N, Nakagawa H, Kita Y, Natsugoe S, Yang Y, Li Z, Wasik M, Klein-Szanto AJ, Rustgi AK, et al: PRMT5 is required for lymphomagenesis triggered by multiple oncogenic drivers. Cancer Discov 5: 288-303,2015.

20. Stopa N, Krebs JE and Shechter D: The PRMT5 arginine methyltransferase: Many roles in development, cancer and beyond. Cell Mol Life Sci 72: 2041-2059, 2015.

21. Kanda M, Shimizu D, Nomoto S, Takami H, Hibino S, Oya H, Hashimoto R, Suenaga M, Inokawa Y, Kobayashi D, et al: Prognostic impact of expression and methylation status of DENN/MADD domain-containing protein 2D in gastric cancer. Gastric Cancer 18: 288-296, 2015.

22. Kanda M, Kodera Y and Sakamoto J: Updated evidence on adjuvant treatments for gastric cancer. Expert Rev Gastroenterol Hepatol 9: 1549-1560, 2015.

23. Sakuramoto S, Sasako M, Yamaguchi T, Kinoshita T, Fujii M, Nashimoto A, Furukawa H, Nakajima T, Ohashi Y, Imamura H, et al; ACTS-GC Group: Adjuvant chemotherapy for gastric cancer with S-1, an oral fluoropyrimidine. N Engl J Med 357: 1810-1820, 2007.

24. Kanda M, Murotani K, Kobayashi D, Tanaka C, Yamada S, Fujii T, Nakayama G, Sugimoto H, Koike M, Fujiwara M, et al: Postoperative adjuvant chemotherapy with S-1 alters recurrence patterns and prognostic factors among patients with stage II/III gastric cancer: A propensity score matching analysis. Surgery 158: 1573-1580, 2015 .

25. Kanda M, Oya H, Nomoto S, Takami H, Shimizu D, Hashimoto R, Sueoka S, Kobayashi D, Tanaka C, Yamada S, et al: Diversity of clinical implication of B-cell translocation gene 1 expression by histopathologic and anatomic subtypes of gastric cancer. Dig Dis Sci 60: 1256-1264, 2015.

26. Kanda M, Shimizu D, Fujii T, Sueoka S, Tanaka Y, Ezaka K, Takami H, Tanaka H, Hashimoto R, Iwata N, et al: Function and diagnostic value of Anosmin-1 in gastric cancer progression. Int J Cancer 138: 721-730, 2016. 
27. Oya $H$, Kanda M, Sugimoto $H$, Shimizu D, Takami $H$, Hibino S, Hashimoto R, Okamura Y, Yamada S, Fujii T, et al: Dihydropyrimidinase-like 3 is a putative hepatocellular carcinoma tumor suppressor. J Gastroenterol 50: 590-600, 2015.

28. Gervasi M, Bianchi-Smiraglia A, Cummings M, Zheng Q, Wang D, Liu S and Bakin AV: JunB contributes to Id2 repression and the epithelial-mesenchymal transition in response to transforming growth factor- $\beta$. J Cell Biol 196: 589-603, 2012.

29. Yan F, Alinari L, Lustberg ME, Martin LK, Cordero-Nieves HM, Banasavadi-Siddegowda Y, Virk S, Barnholtz-Sloan J, Bell EH, Wojton $\mathrm{J}$, et al: Genetic validation of the protein arginine methyltransferase PRMT5 as a candidate therapeutic target in glioblastoma. Cancer Res 74: 1752-1765, 2014.

30. Smil D, Eram MS, Li F, Kennedy S, Szewczyk MM, Brown PJ, Barsyte-Lovejoy D, Arrowsmith CH, Vedadi M and Schapira M: Discovery of a dual PRMT5-PRMT7 inhibitor. ACS Med Chem Lett 6: 408-412, 2015.

31. Hu M, Xia M, Chen X, Lin Z, Xu Y, Ma Y and Su L: MicroRNA141 regulates Smad interacting protein 1 (SIP1) and inhibits migration and invasion of colorectal cancer cells. Dig Dis Sci 55: 2365-2372, 2010.

32. Okugawa $Y$, Inoue $Y$, Tanaka K, Kawamura M, Saigusa $S$, Toiyama Y, Ohi M, Uchida K, Mohri Y and Kusunoki M: Smad interacting protein 1 (SIP1) is associated with peritoneal carcinomatosis in intestinal type gastric cancer. Clin Exp Metastasis 30: 417-429, 2013

33. Karihtala P, Auvinen P, Kauppila S, Haapasaari KM, JukkolaVuorinen A and Soini Y: Vimentin, zeb1 and Sip1 are up-regulated in triple-negative and basal-like breast cancers: Association with an aggressive tumour phenotype. Breast Cancer Res Treat 138: 81-90, 2013.

34. Thakur R, Trivedi R, Rastogi N, Singh M and Mishra DP: Inhibition of STAT3, FAK and Src mediated signaling reduces cancer stem cell load, tumorigenic potential and metastasis in breast cancer. Sci Rep 5: 10194, 2015.
35. Wang T, Yuan J, Zhang J, Tian R, Ji W, Zhou Y, Yang Y, Song W, Zhang F and Niu R: Anxa2 binds to STAT3 and promotes epithelial to mesenchymal transition in breast cancer cells. Oncotarget 6: 30975-30992, 2015.

36. Kim BR, Oh SC, Lee DH, Kim JL, Lee SY, Kang MH, Lee SI, Kang S, Joung SY and Min BW: BMP-2 induces motility and invasiveness by promoting colon cancer stemness through STAT3 activation. Tumour Biol 36: 9475-9486, 2015.

37. Taylor MA, Davuluri G, Parvani JG, Schiemann BJ, Wendt MK, Plow EF, Schiemann WP and Sossey-Alaoui K: Upregulated WAVE3 expression is essential for TGF- $\beta$-mediated EMT and metastasis of triple-negative breast cancer cells. Breast Cancer Res Treat 142: 341-353,2013.

38. Gao J, Zhu Y, Nilsson M and Sundfeldt K: TGF- $\beta$ isoforms induce EMT independent migration of ovarian cancer cells. Cancer Cell Int 14: 72, 2014.

39. Kanda M, Nomoto S, Oya H, Shimizu D, Takami H, Hibino S, Hashimoto R, Kobayashi D, Tanaka C, Yamada S, et al: Dihydropyrimidinase-like 3 facilitates malignant behavior of gastric cancer. J Exp Clin Cancer Res 33: 66, 2014.

40. Yoo CH, Noh SH, Shin DW, Choi SH and Min JS: Recurrence following curative resection for gastric carcinoma. Br J Surg 87: 236-242, 2000

41. Shen L, Shan YS, Hu HM, Price TJ, Sirohi B, Yeh KH, Yang YH, Sano T, Yang HK, Zhang X, et al: Management of gastric cancer in Asia: Resource-stratified guidelines. Lancet Oncol 14: e535-e547, 2013.

42. Kanda M, Nomoto S, Oya H, Hashimoto R, Takami H, Shimizu D, Sonohara F, Kobayashi D, Tanaka C, Yamada S, et al: Decreased expression of prenyl diphosphate synthase subunit 2 correlates with reduced survival of patients with gastric cancer. J Exp Clin Cancer Res 33: 88, 2014. 